\title{
ERJ
}

Engineering Research Journal

Faculty of Engineering

Minoufiya University

\section{Effect of adsorption to desorption air mass ratio on the performance of double bed desiccant dehumidification system}

\author{
Y.A.F. El-Samadony \\ Mechanical Power Engineering Department, Faculty of Engineering, Tanta University, Egypt \\ samadony25@yahoo.co.uk
}

\begin{abstract}
In the present work, experimental investigation of the performance of double bed desiccant dehumidification system has been carried out. The two desiccant beds operate simultaneously. When one of the two beds functions as an adsorber, the second operates as a regenerator. In this investigation, silica gel is applied as the desiccant material. Hot air from an air heater is blown through the regenerated bed using an air blower. System performance at different conditions of flowing air is demonstrated. The experimental tests were carried out at different conditions of inlet air and initial bed parameters. Temperature and humidity of air at the inlet and exit of the bed were measured. The effect of adsorption to desorption air mass ratio is examined. In the present study, it is found that $63 \%$ regeneration to total air mass ratio is the optimum value.
\end{abstract}

Keywords: Desiccant, Dehumidification, Adsorption, Regeneration, Silica gel

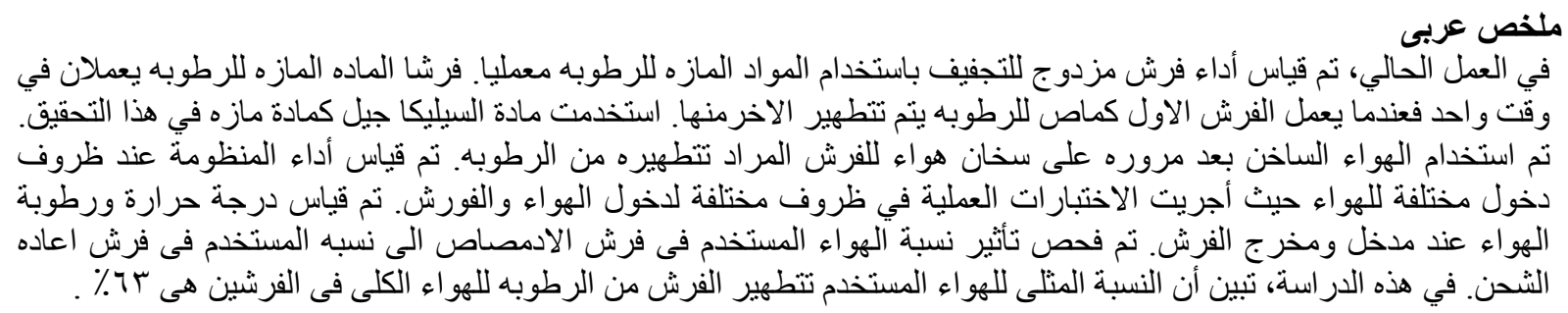

\section{INTRODUCTION}

Desiccants are solid or liquid materials which have the property of extracting and holding water vapour which brought into contact with them. The principle behind desiccant dehumidification is that the desiccant is exposed to moisture laden air, from which it is extracted by the desiccant and held. The saturated desiccant is heated (regenerated), which drives off the collected moisture into the exhaust air stream. The regenerated desiccant is ready for use again. The heat required for regenerating the weak desiccants can be supplied by fossil fuel, waste heat, or any form of low-grade thermal energy, and most of the time, solar energy is used in such processes [13]. Desiccants are preferably used for all applications where constant humidity values are required and where a high dehumidification has to be obtained at low temperatures. The most commonly used desiccant is silica gel which can adsorb and hold moisture up to a maximum of 40 percent of its weight in moisture and does not swell in size as it adsorbs moisture.

Solid desiccant cooling and dehumidification systems have received considerable attention in the past several years as alternatives or supplements to conventional vapor compression machines for air conditioning of buildings and spaces that have high latent loads [4]. Also, several studies have been conducted on the operation of the desiccant dehumidification employing evaporative cooling processes [5-8]. The research activities in this sector are still increasing to improve the performance and solve the problems that make these systems not yet ready to compete with the conventional air conditioning systems.

EL-Samadony et. al [9] studied experimentally the dynamic performance of single desiccant bed during adsorption processes. They also studied the effect of air mass flow rate and air regeneration temperature on the global adsorption performance. Moreover, they divided adsorption time into four periods namely rehabilitation period, ascending period, uppermost period and descending period, Fig 1 , and studied the effect of the operating parameters on each period. They found that "Rehabilitation period" in adsorption process could be eliminated if the air mass flow rate is greater than $1.92 \mathrm{~kg} / \mathrm{hr}$ per $\mathrm{kg}$ of silica gel. With the same techniques, the dynamic performance of single desiccant bed during desorption processes are studied [10] and [11].

Hamed [12] studied theoretically and experimentally the transient adsorption characteristics of vertical packed porous bed. He investigated a theoretical model to describe the effect of independent parameters (time, and vertical distance) on the vertical gradient of adsorbable fluid in a desiccant bed. Hamed et al. [13] studied experimentally the transient adsorption/desorption 
Effect of adsorption to desorption air mass ratio on the performance of double bed desiccant dehumidification system

\section{Y.A.F. El-Samadony}

characteristics of solid desiccant in a vertical fluidized bed. They found that the relation between the adsorbed water and the moisture fraction for material depends on the thermo-physical properties of the solid adsorbate-adsorbent pair. In silica gel the relation can be expressed as a linear function. They carried out a comparison between packed and fluidized bed adsorption. The test results showed that the performance of the bed under fluidization condition is better than packed one. On the other hand, accumulation of the heat of adsorption in packed bed results in an increase in the bed temperature when compared with that of fluidized bed.

Kabeel [14] studied the effect of design and operating parameters on the performance of a multilayer desiccant packed bed theoretically and experimentally. He compared his experimental and theoretical results with that of Abd-Elrahman [15], and the results showed reasonable agreement.

From the previous review, the following points need to be studied for double bed desiccant dehumidification system. The first one is the optimum switching time between the two beds i.e. switching time between adsorption and desorption processes. The second one is the effect of the ratio between air mass flow rates for the adsorption and desorption processes. In the present study, an experimental unit has been designed and installed to cover these points. Several objectives are formulated to address the overall goal of the present study. These objectives are:

1- Design and installation of a double bed desiccant system coupled with an air heater for regeneration of silica gel in the bed.

2- Study and discussion of the proposed system operation at different conditions.

\section{EXPERIMENTAL WORK}

The experimental unit has been designed and installed to evaluate the effect of design and operating parameters on the performance of the present system. A schematic diagram of the double bed adsorption/desorption air dehumidification system is illustrated in Figure (2). The system consists of two desiccant beds and eight control valves. Silica gel $(95 \%$ White $+5 \%$ Blue, with 3.5 $\mathrm{mm}$ bead diameter) is used as desiccant. Beds dimension is $21 \mathrm{~cm}$ in diameter and $90 \mathrm{~cm}$ in height.

The two beds exchange the operation mode with the help of control valves [16]. As shown in Figure (2A), one of the two beds B2 operates as an adsorber, while the other bed B1 functions as a desorber. During this mode of operation, valves $1,2,3$ and 4 are kept open while the other four valves 5, 6, 7 and 8 are maintained close. To exchange the function between the two beds, the valves condition is reversed, as shown in Figure (2-B), that is, valves 1, 2, 3 and 4 are closed and the others are opened. In this case, the bed B1 operates as an adsorber and the second bed as a disorder. The operation schedule of control valves is given in Table (1). The heat and mass transfer in the bed is individually analyzed by using a computer program with two different switching control schemes

The adsorption and desorption processes were studied for double beds at different operating conditions such as air flow rate, hot air regeneration temperature and humidity ratio. The blower is used to introduce the atmospheric air to the system. The heater is used to regenerate the desiccant bed, silica gel, by heating the air. A variac (transformer) is used to change the regeneration hot temperature by changing the electrical heater's supplied volt. The amount of air flow rate to the system is controlled by the valves opening position and measured by means of hot wire anemometer which gives the velocity directly in $\mathrm{m} / \mathrm{s}$. Two valves are used to control the amount of air flow rate, valve 1 (for bid 2) and 7 (for bid 1) during adsorption process while valve 3 (for bid 1) and 5 (for bid 2) during regeneration process. Air outlet conditions (dry bulb temperature, dew point temperature and relative humidity) were measured and recorded by means of a data logger every a constant time intervals 10 seconds. The humidity ratio of air was calculated from its dry bulb temperature and relative humidity [17].

The switching between case A and case B (as shown in Figure (2) will take place when the value of the air humidity ratio at outlet is close to that at inlet. This is because, at this situation, desiccant bed does not has any ability to adsorb or desorp water vapour and consquantity, switching the valves is essential. To reduce the amount of heat lost from the desiccant bed during the regeneration process, the bed hase covered with an insulated jacket. Adsorption capacity percentage was calculated as the ratio between outlet to inlet air humidity ratio. However, desorption capacity percentage was calculated as the ratio between inlet to outlet air humidity ratio.

\section{RESULTS AND DISCUSSION}

The performance of desiccant packed bed during adsorption and regeneration processes was evaluated by conducting a series of runs with different inlet conditions of air streams, listed in table (2). This study included the effect of the hot air regeneration temperature and regeneration to adsorption air mass flow rate ratio on regeneration and adsorption time

\section{Adsorption and desorption processes}

Figures (3) and (4) illustrate the variation of the outlet to inlet air humidity ratio with the adsorption 
Effect of adsorption to desorption air mass ratio on the performance of double bed desiccant dehumidification system

\section{Y.A.F. El-Samadony}

or desorption time for different air regeneration temperatures at air mass flow rate of $0.77 \mathrm{~kg} / \mathrm{min}$ and $0.71 \mathrm{~kg} / \mathrm{min}$ respectively. As expected, it can be seen from these figures that the graphical relationships between outlet to inlet air humidity ratio and adsorption time seemed to be look like "U" curve i.e. the outlet to inlet air humidity ratio firstly decreases and then increases with time. In contrary, relation betwwen the outlet to inlet air humidity ratio and desorption time seemed to be look like " $\cap$ " curve i.e. the outlet to inlet air humidity ratio firstly increases and then decreases with time. It could be seen also that the regeneration time is less than that for the adsorption time. Moreover, as the regeneration temperature and/or air mass flow rate increases regeneration time decreases and its ability to adsorb or desorb water vapour increases.

\section{Air mass ratio for adsorption/desorption processes}

Figures (5) to (8) illustrate the variation of the outlet to inlet air humidity ratio with the adsorption or desorption time for different air mass ratios in case of adsorption and regeneration processes at a regeneration temperatures of 40, 50, 66 and $77{ }^{\circ} \mathrm{C}$ respectively. It can be seen from these figures that as regeneration air mass ratio increases (i.e. adsorption air mass ratio decreases) regeneration and adsorption time decreases and increases respectively and vice versa. This is because as the amount of air mass flow rate increases, air heat capacity increases. It can be seen also from these figures that as regeneration temperature increases regeneration time decreases. Also, it can be seen, from these Figures that the "Rehabilitation period" (adsorption or regeneration processes start at $t>0$ ) decreases as the amount of air mass flow rate and air regeneration temperature increase. This is because as the amount of air mass flow rate increases air heat capacity increases and hence this could increase silica gel temperature in a shorter period. It can be noted that for air regeneration temperature of $77{ }^{\circ} \mathrm{C}$, Figure (8), as the regeneration to total air mass ratio is increased from $37 \%$ to $63 \%$, regeneration time decreased by $42.86 \%$.

\section{Optimal air mass ratio and switching time}

Regeneration (desorption) process has a great influence on the follower adsorption process (main objective process). On the other hand, incomplete adsorption process will not have any negative effect on the follower regeneration process. Therefore, the selected air mass ratio must be the value which its regeneration time at least is equal to the adsorption time. It will be much better if the regeneration time is less than that for the adsorption. At this case, the ascending adsorption period, the period at which humidification efficiency is a maximum, will be used. In the present study, it can be noted from Figures ( 5 to 8 ) that the best air mass ratio occurs at $63 \%$ regeneration to the total air mass ratio i.e. $37 \%$ adsorption to the total air mass ratio

\section{Experimental uncertainty analysis}

In the present section, the uncertainty analysis of the experimental results is obtained according to Holman [18]. The measurements are made to obtain the following results: air humidity ratio, $\mathrm{w}$, and adsorption/desorption capacity percentage. These results are function of two independent variables; dry bulb temperature, $t$, and relative humidity, $\varphi$. Thus

$$
\mathrm{w}=\mathrm{w}(\mathrm{t}, \varphi)
$$

Let $\mathrm{W}_{\mathrm{w}}$ be the uncertainty in the result and $\mathrm{W}_{\mathrm{t}}$ and $\mathrm{W} \varphi$, be the uncertainties in the independent variables. The uncertainty in results is calculated according to the equation proposed by [17] as follows:

$$
W_{W}=\left[\left(\frac{\partial w}{\partial T} W_{t}\right)^{2}+\left(\frac{\partial W}{\partial \phi} W_{\phi}\right)^{2}\right]^{\frac{1}{2}}
$$

where

$W_{t} \quad$ Uncertainty associated with the data logger dry bulb temperature $= \pm 0.1{ }^{0} \mathrm{C}$

$W_{\phi} \quad$ Uncertainty associated with the data logger relative humidity $= \pm 3 \%$

Calculations show that uncertainty in calculating air humidity ratio and adsorption/desorption capacity percentage are approximately $0.112 \%$ and $0.147 \%$ respectively

\section{CONCLUSIONS}

Based on the present results, the following conclusions can be presented:

1. As regeneration air mass ratio increases (i.e. adsorption air mass ratio decreases) regeneration and adsorption time decreases and increases respectively and vice versa

2. switching time should be after full regeneration process

3. It is better to have regeneration to total air mass ratio greater than that for adsorption to total air mass ratio. In the present study $63 \%$ regeneration to total air mass ratio is the optimum

\section{REFERENCES}

[1] "Development of solar desiccant humidifier", (1978), Technical progress report, No 87-149571. Research Manufacturing Company of California

[2] M. Dupont, B. Celestine, P.H. Nguyen, J. Merigoux , and B. Brandon, (1994), "Desiccant 
Effect of adsorption to desorption air mass ratio on the performance of double bed desiccant dehumidification system

Y.A.F. El-Samadony

solar air conditioning in tropical climates : I dynamic experimental and numerical studies of silica gel and activated alumina", Solar Energy, vol. 52 (6), PP. 509-517

[3] Surajitr Pramuang and R.H.B. Exell, (2007), “The regeneration of silica gel desiccant by air from a solar heater with a compound parabolic concentrator", Renewable Energy, vol. 32, PP 173-182

[4] Pesaran A. A. and Bingham C. E. (1989) "Testing of Novel Desiccant Materials and Dehumidifier Matrices for Desiccant Cooling Applications," SERI/TP-254-3478.

[5] W. Pridasawas, (2006), "Solar-Driven Refrigeration Systems with Focus on the Ejector Cycle", Doctoral Thesis, Stockholm, October 2006

[6] Waugaman, D.G., Kini, A., Kettleborough, C.F., (1993), "A review of desiccant cooling systems", Journal of Energy Resources Technology, 115, 1-8.

[7] Mazzei, P., Minichiello, F., Palma, D., (2005), "HVAC dehumidification systems for thermal comfort: a critical review", Applied Thermal Engineering 25, 677-707.

[8] Daou, K., Wang, R., Xia, Z., (2006), "Desiccant cooling air conditioning: a review. Renewable and Sustainable Energy Reviews 10, 55-77

[9] Y. A. F. El-Samadony, A. M. Hamed and A. E. Kabeel, (2013), "Dynamic Performance Evaluation of Single Bed Desiccant Dehumidification System," International Journal of Renewable and Sustainable Energy, Vol. 2, No. 1, pp. 18-25.

[10] Yasser A. F. El-Samadony, A M. Hamed, and Abd enaby Kabeel (2013) "performance evaluation of single bed desiccant desorption process", Natural Resources Journal, Vol. 4 (1), PP. 69-75.

[11] Kuei-Sen Chang, Hui-Chun Wang, and TsairWang Chung,(2004) " Effect of regeneration conditions on the adsorption dehumidification process in packed silica gel beds", Applied Thermal Engineering, Vol. 24, PP735-742.

[12] Hamed, A. M. (2002) "Theoretical and Experimental Study on the Transient Adsorption Characteristics of a Vertical Packed Porous Bed," Renewable Energy, 27, 525-541

[13] Hamed. A. M. Abd-elrahman, W. R. and ElEmam, S. H. (2010) "Experimental study of the transient adsorption/desorption characteristics of silica gel particles in fluidized bed," Energy, 35, 6, 2468-2483.

[14] Kabeel, A. E. (2009) "Adsorption-Desorption Operations of Multilayer Desiccant Packed Bed for Dehumidification Applications," Renewable Energy, 34, 255-265.

[15] Abd-Elrahman, W. R. (2005) "Theoretical and Experimental Study on the Performance of a Fluidized Air Dryer,” M.Sc. Thesis. Mechanical Engineering Department, Mansoura University, Egypt.

[16] Ramzy A. K., Hamed A. M, Awad, M. M. and Bekheit M. M. (2008) "Theoretical and Experimental Investigation on the Radial Flow Desiccant Dehumidification Bed," Applied Thermal Engineering, 28, 75-85.

[17] ASHRAE Handbook-Applications (1997), American society of heating, ventilation and air conditioning Engineer, 1791 Tullie Circle, Atlanta, GA 30329, USA

[18] Holman JP, Experimental method for engineers, 6th ed. Singapore: McGraw-Hill; 1994

\section{NOMENCLATURE}

B1 Bed number one

B2 Bed number two

Q air mass flow rate, $\mathrm{kg} / \mathrm{s}$

$\mathrm{t}$ air dry bulb temperature, ${ }^{\circ} \mathrm{C}$

$\mathrm{T}=\mathrm{t}_{\mathrm{rg}}$ Inlet hot air regeneration temperature, ${ }^{\circ} \mathrm{C}$

w air humidity ratio, $\mathrm{g} / \mathrm{kg}$

Greek symbols

$\varphi \quad$ Air relative humidity, $\%$

\section{Subscripts}

1 Inlet condition number 1

2 Inlet condition number 2

3 Inlet condition number 3

4 Inlet condition number 4

Table (1)

the operation schedule of control valves [11]

\begin{tabular}{|l|l|l|l|}
\hline Case & Valves & 1 to 4 & 5 to 8 \\
\hline A & $\begin{array}{l}\text { B2 Adsorber } \\
\text { B1 Desorber }\end{array}$ & opened & closed \\
\hline B & $\begin{array}{l}\text { B2 Desorber } \\
\text { B1 Adsorber }\end{array}$ & closed & opened \\
\hline
\end{tabular}

Table 2

Air mass ratio and inlet regeneration temperature

\begin{tabular}{|c|c|c|c|}
\hline \multicolumn{4}{|c|}{ Air mass ratio } \\
\hline $0.37,0.42,0.46,0.50,0.54,0.58,0.63$ \\
\hline \multicolumn{3}{|c|}{ inlet regeneration temperature, ${ }^{\circ} \mathrm{C}$} \\
\hline $\mathrm{T} 1$ & $\mathrm{~T} 2$ & $\mathrm{~T} 3$ & $\mathrm{~T} 4$ \\
\hline 40 & 50 & 66 & 75 \\
\hline
\end{tabular}


Effect of adsorption to desorption air mass ratio on the performance of double bed desiccant dehumidification system

Y.A.F. El-Samadony

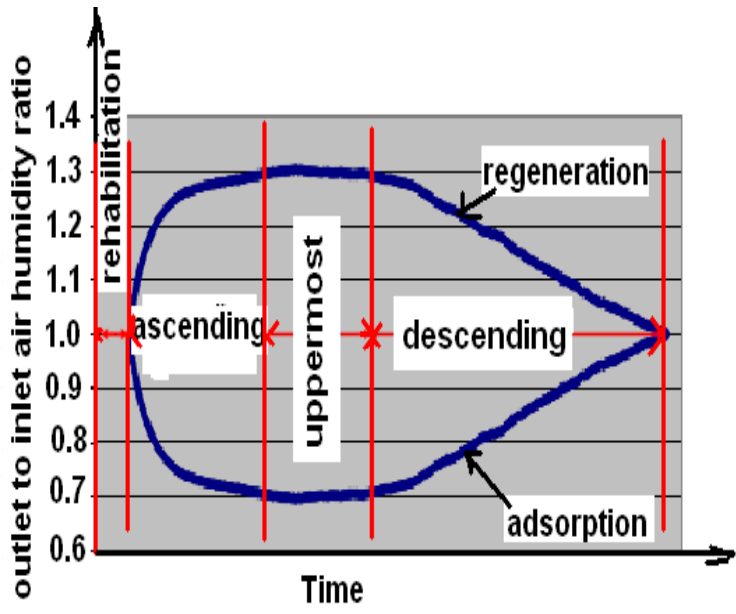

Figure (1) rehabilitation, ascending, uppermost and descending period defination

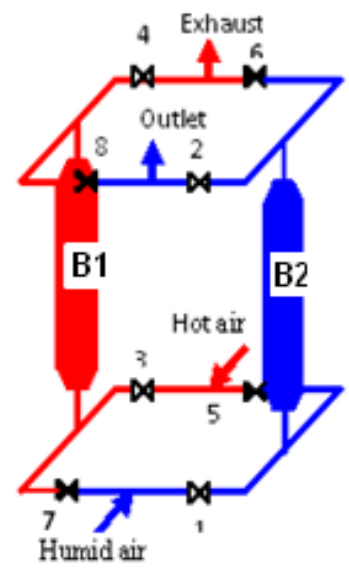

$\bowtie \quad$ Opened valve

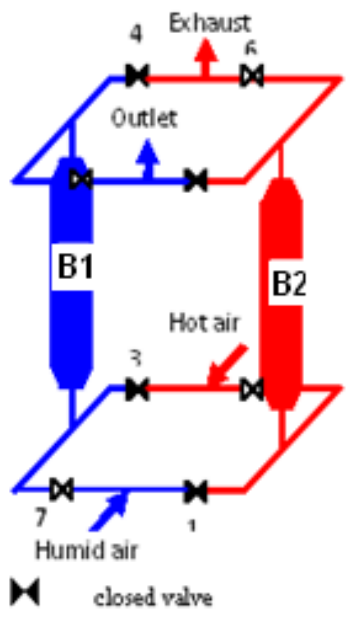

$(1-\mathrm{A})$

Figure (2) Flow diagram of double-bed adsorptiondesorption air dehumidification system

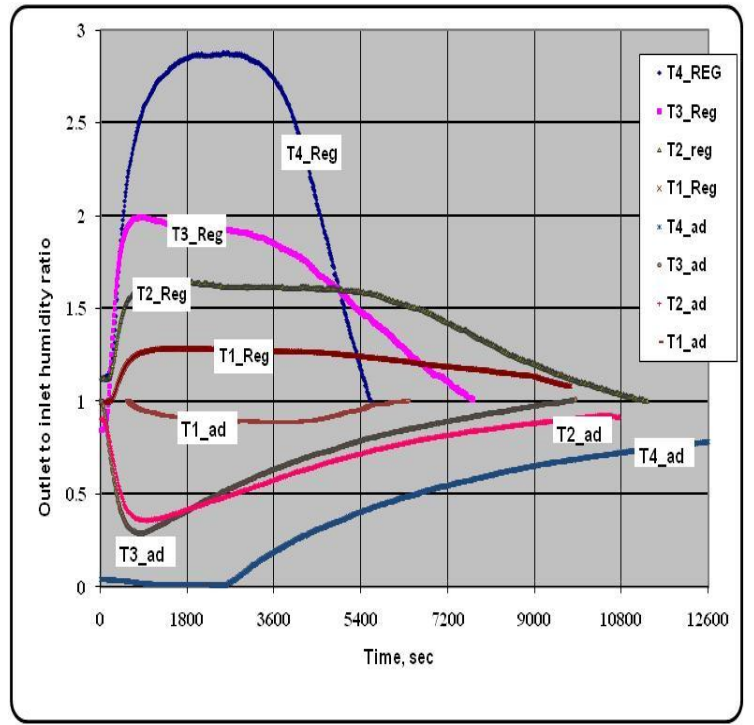

Figure (3) the variation of the outlet to inlet air humidity ratio with the adsorption/desorption time for different air regeneration temperatures at air mass flow rate of $0.77 \mathrm{~kg} / \mathrm{min}$

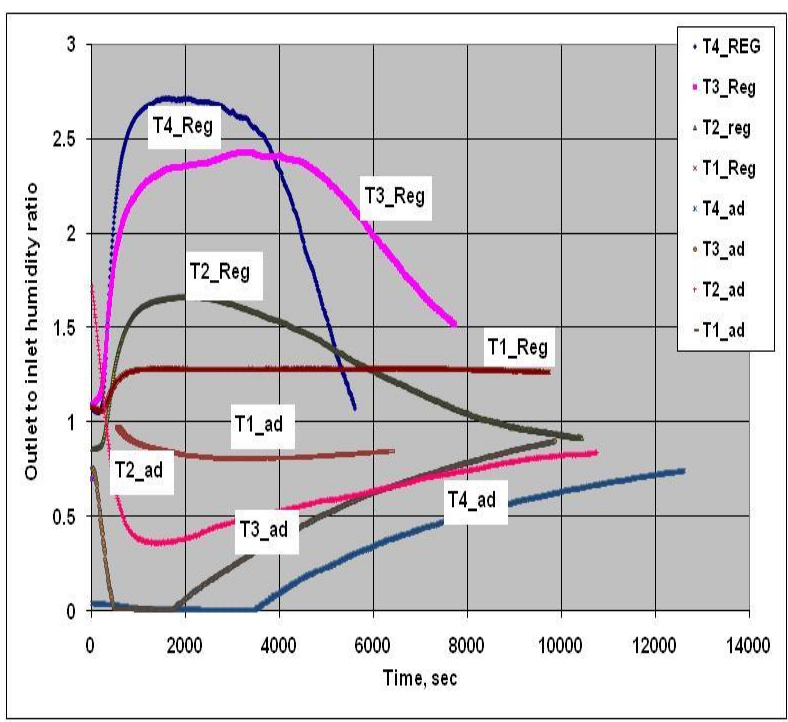

Figure (4) the variation of the outlet to inlet air humidity ratio with the adsorption or desorption time for different air regeneration temperatures at air mass flow rate of $0.71 \mathrm{~kg} / \mathrm{min}$ 
Effect of adsorption to desorption air mass ratio on the performance of double bed desiccant dehumidification system

Y.A.F. El-Samadony

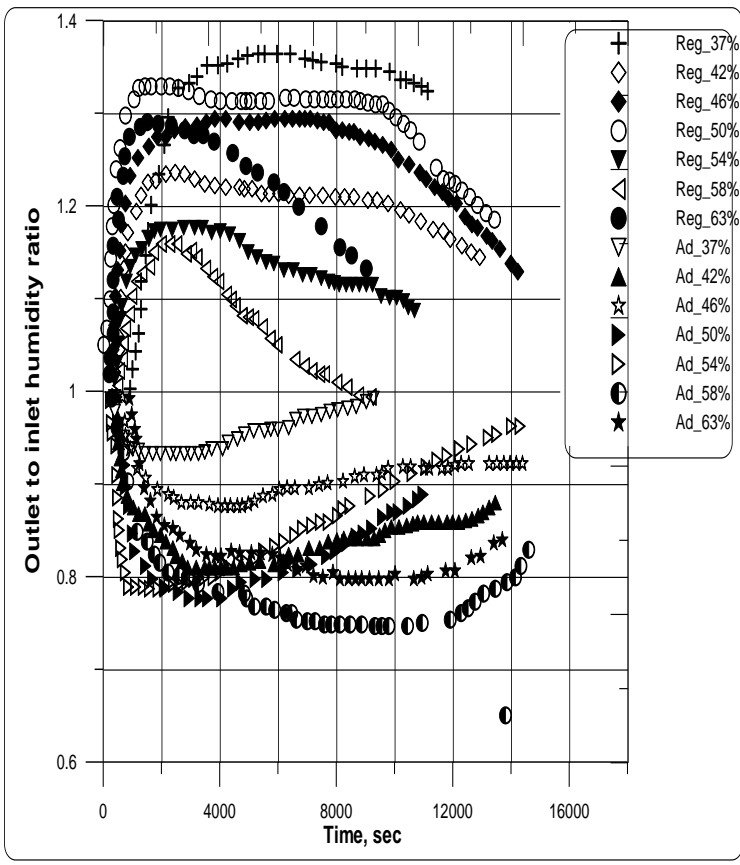

Figure (5) the variation of the outlet to inlet air humidity ratio with the adsorption or desorption time for different air mass ratios and at regeneration temperatures of $40^{\circ} \mathrm{C}$

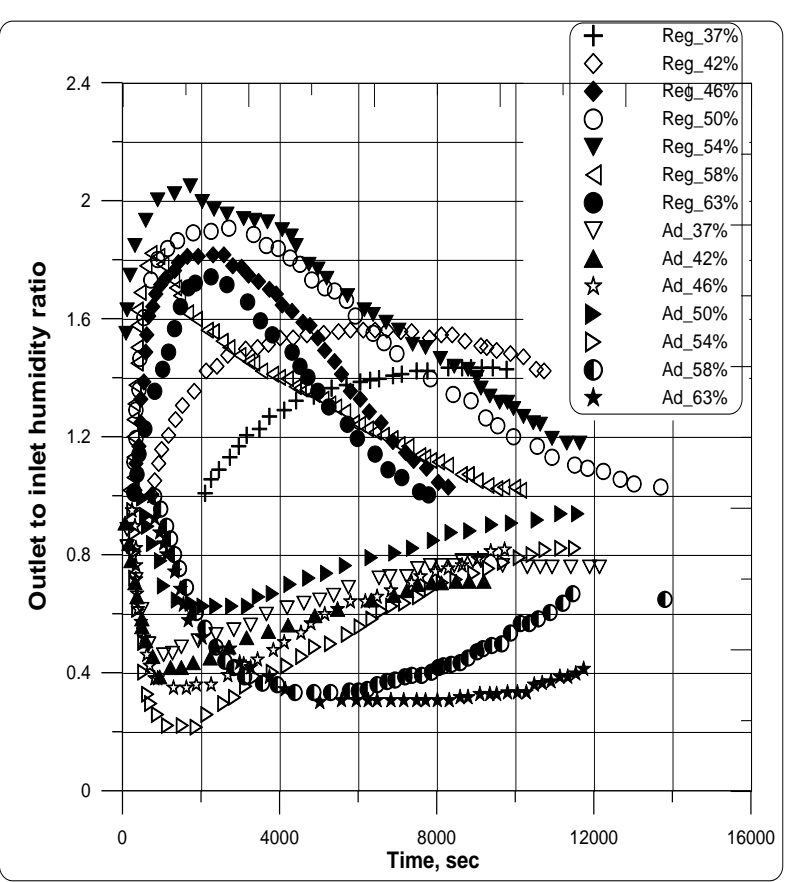

Figure (6) the variation of the outlet to inlet air humidity ratio with the adsorption or desorption time for different air mass ratios and at regeneration temperatures of $50{ }^{\circ} \mathrm{C}$

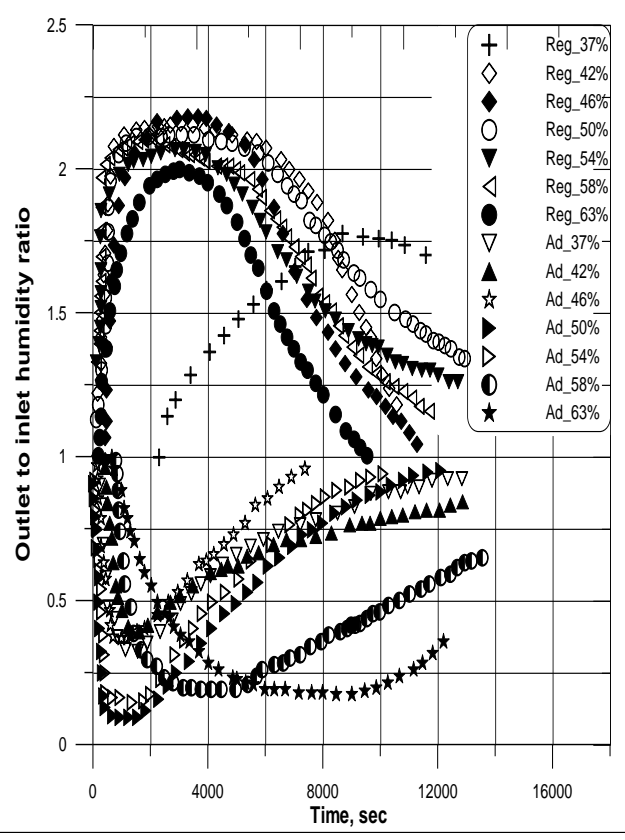

Figure (7) the variation of the outlet to inlet air humidity ratio with the adsorption or desorption time for different air mass ratios and at regeneration temperatures of $66^{\circ} \mathrm{C}$

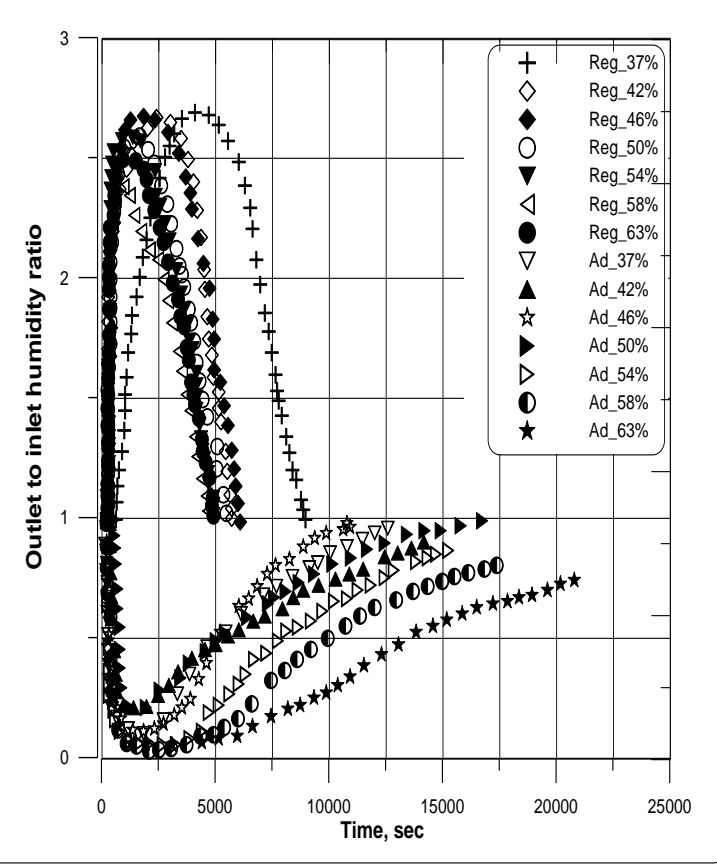

Figure (8) the variation of the outlet to inlet air humidity ratio with the adsorption or desorption time for different air mass ratios and at regeneration temperatures of $75^{\circ} \mathrm{C}$ 